\title{
Software for Spatial Statistics
}

\section{Edzer Pebesma}

University of Münster

\author{
Roger Bivand \\ Norwegian School \\ of Economics
}

\author{
Paulo Justiano Ribeiro \\ UFPR Brazil
}

\begin{abstract}
We give an overview of the papers published in this special issue on spatial statistics, of the Journal of Statistical Software. 21 papers address issues covering visualization (micromaps, links to Google Maps or Google Earth), point pattern analysis, geostatistics, analysis of areal aggregated or lattice data, spatio-temporal statistics, Bayesian spatial statistics, and Laplace approximations. We also point to earlier publications in this journal on the same topic.
\end{abstract}

Keywords: spatial statistics, special issue, software, R.

\section{Introduction}

As a reaction to the steadily growing availability of open source software for spatial statistics, the success of the Journal of Statistical Software, and the need for papers on scientific software in general, in February 2013 we issued a call for papers for a special issue on spatial statistics. ${ }^{1}$ In total, 21 papers submitted to this call were accepted, and are bundled in this special issue. The papers in this issue largely focus on packages for the $R$ system for statistical computing $(R$ Core Team 2014). This may be either because the special issue call was best circulated among $\mathrm{R}$ users and developers, or perhaps because most scientific software about spatial statistics is currently being developed in $\mathrm{R}$.

Meaningful statistical analysis of spatial or spatio-temporal data (Stasch, Scheider, Pebesma, and Kuhn 2014) needs to discern whether observations represent records of discrete entities (objects in space, events in time) such as disease cases or tornados, or observations on continuous phenomena, or fields, such as air temperature or wind speed. In the spatial statistics literature, the first type of data is usually refered to as point patterns, the second as geostatistical data. A third type of data arises when either entities or field values are aggregated

\footnotetext{
${ }^{1}$ As on, for example: https://stat.ethz.ch/pipermail/r-sig-geo/2013-February/017419.html.
} 
over regular or irregular areas, such as grid cells or administrative regions, and form lattice or areal data.

We will briefly discuss the contributions in this special issue under their sub-area visualization, point patterns, geostatistics, and lattice or areal data, and mention with each paper whether they involve Bayesian methods and spatio-temporal processes.

\section{Visualization}

The first two papers present software to create micromaps. Payton, McManus, Weber, Olsen, and Kincaid (2015) present ways to create linked micromaps, and Pickle, Pearson Jr., and Carr (2015) present micromaps for US State data.

The two following papers both discuss how $\mathrm{R}$ data can be plotted on external mapping systems. Loecher and Ropkins (2015) discuss ways to do this using Google maps, while Hengl, Roudier, Beaudette, and Pebesma (2015) present ways to convert R data to KML, a display format the dominant viewer of which is Google Earth.

Older papers published in the Journal of Statistical Software on the topic of visualizing spatial data include Josselin (2005); Tanimura, Kuroiwa, and Mizota (2006) and Laurent, RuizGazen, and Thomas-Agnan (2012).

\section{Point patterns}

Three papers deal with the analysis of point patterns. Pélissier and Goreaud (2015) present an efficient way to compute the K-function of point patterns in irregular-shaped sampling windows. Taylor, Davies, Rowlingson, and Diggle (2015) present methods for spatial, spatiotemporal and multivariate log-Gaussian Cox processes. Brown (2015) shows how log-Gaussian Cox processes can be modeled using Laplace approximation.

Besides the highly cited Baddeley and Turner (2005), earlier papers published in the Journal of Statistical Software on point pattern analysis include Harte (2010); Taylor, Davies, Rowlingson, and Diggle (2013); Gabriel, Rowlingson, and Diggle (2013) and Baddeley, Turner, Mateu, and Bevan (2013).

\section{Geostatistics}

RandomFields is a package that has been on the Comprehensive R Archive Network (CRAN) since 2001. Schlather, Malinowski, Menck, Oesting, and Strokorb (2015) describe recent developments in RandomFields that concern the modeling of multivariate random fields. Padoan and Bevilacqua (2015) analyze random fields by composite likelihood methods, an approach motivated by large data sets. Paciorek, Lipshitz, Zhuo, Prabhat, Kaufman, and Thomas (2015) present and analyze parallelized Gaussian process calculations. Jing and De Oliveira (2015) present an R package for the analysis of count data. Finley, Banerjee, and E.Gelfand (2015) present Bayesian methods for univariate and multivariate data. Sigrist, Künsch, and Stahel (2015) present a modeling approach where the data are assumed to come from a stochastic advection-diffusion process. Bakar and Sahu (2015) deal with a Bayesian approach to modeling spatio-temporal data. Brown (2015) presents interfaces that simplify the use of 
Bayesian methods, using MCMC or Laplace approximations, based on other packages.

Earlier papers published in the Journal of Statistical Software on the topic of geostatistics include Barry (1996) - the first paper published in the Journal, Finley, Banerjee, and Carlin (2007); Smith, Yan, and Cowles (2008); Davies and Bryant (2013); Peterson and Ver Hoef (2014) and Ver Hoef, Peterson, Clifford, and Shah (2014).

\section{Lattice or areal data}

Gaudart, Graffeo, Coulibaly, Barbet, Rebaudet, Dessay, Doumbo, and Giorgi (2015) present methods for spatial partitioning, i.e. to classify points into areas based on attribute similarity. Gollini, Lu, Charlton, Brunsdon, and Harris (2015) present software that extends geographically weighted regression to broader model descriptions, including summary statistics, principal components, regression and discriminant analysis. Bivand and Piras (2015) compare implementations of estimation methods for spatial econometrics accross different systems, including R, Python (PySAL), Stata and MATLAB. Gerber and Furrer (2015) describe pitfalls in the implementation of Bayesian hierarchical modeling of areal count data. Lindgren and Rue (2015) describe Bayesian spatial modeling with the R package INLA, which is not on $\mathrm{CRAN}^{2}$ but is nevertheless open source and widely used. Bivand, Gómez-Rubio, and Rue (2015) present some spatial statistical extensions to R package INLA. Finally, Umlauf, Adler, Kneib, Lang, and Zeileis (2015) present R2BayesX, an R interface to BayesX, for structured additive regression models.

Earlier papers published in the Journal of Statistical Software on the topic of analyzing lattice data include Brezger, Kneib, and Lang (2005); Piras (2010); Almquist (2010); Davies, Hazelton, and Marshall (2011); Millo and Piras (2012), and Lee (2013).

\section{Discussion}

This special issue demonstrates that spatial statistics is a lively area where development of new statistical methods and visualization techniques and their application to real data sets go hand in hand with the development of software needed to realize this. Publishing the software and the code underlying the papers further enables the readership to reproduce this and experiment with using the software on their own data.

The special issue process has enabled the authors to look at one anothers' work in cases where mutual reviews made sense, and has also triggered (and in some cases forced) authors to look at their software developments in the broader context of what others have developed previously. Although the concept of the software paper is still in its early days, we do feel that as in methods papers, publication of software requires authors to explain the need for, or added value of their contribution in the context of what has been done before.

Several papers published in this issue build software systems from scratch (R), whereas others build systems by combining existing packages, creating new interfaces: Hengl et al. (2015) and Loecher and Ropkins (2015) interface spatial data in R to popular virtual globe and web mapping systems, Bivand et al. (2015) build new models that extend the INLA package, Brown (2015) presents two packages that simplify the use of Bayesian methods for Gaussian

\footnotetext{
${ }^{2}$ It can be found on http://www.r-inla.org/.
} 
and point processes, building on other packages such as geoR and INLA.

For completeness, we mention a number of earlier papers that were published in the Journal of Statistical Software on topic areas that do not directly fall in the categories dealt with in Sections 3-5. They include papers in the area of ecology Calenge (2007); Goslee and Urban (2007), in the area of handling and analyzing spatiotemporal data Pebesma (2012); Leibovici (2010), spatial sampling Bowman, Gibson, Scott, and Crawford (2010), remote sensing Goslee (2011), and modeling solar radation Perpiñán (2012).

\section{References}

Almquist ZW (2010). "US Census Spatial and Demographic Data in R: The UScensus2000 Suite of Packages." Journal of Statistical Software, 37(6), 1-31. URL http: //www.jstatsoft.org/v37/i06/.

Baddeley A, Turner R (2005). "spatstat: An R Package for Analyzing Spatial Point Patterns." Journal of Statistical Software, 12(6), 1-42. URL http://www. jstatsoft.org/v12/i06/.

Baddeley A, Turner R, Mateu J, Bevan A (2013). "Hybrids of Gibbs Point Process Models and Their Implementation." Journal of Statistical Software, 55(11), 1-43. URL http: //www.jstatsoft.org/v55/i11/.

Bakar KS, Sahu SK (2015). "spTimer: Spatio-Temporal Bayesian Modeling Using R." Journal of Statistical Software, 63(15), 1-32. URL http://www. jstatsoft.org/v63/i15/.

Barry R (1996). "A Diagnostic to Assess the Fit of a Variogram Model to Spatial Data." Journal of Statistical Software, 1(1), 1-11. URL http://www.jstatsoft.org/v01/i01.

Bivand R, Piras G (2015). "Comparing Implementations of Estimation Methods for Spatial Econometrics." Journal of Statistical Software, 63(18), 1-36. URL http://www. jstatsoft.org/v63/i18/.

Bivand RS, Gómez-Rubio V, Rue H (2015). "Spatial Data Analysis with R-INLA with Some Extensions." Journal of Statistical Software, 63(20), 1-31. URL http://www. jstatsoft. org/v63/i20/.

Bowman AW, Gibson I, Scott EM, Crawford E (2010). "Interactive Teaching Tools for Spatial Sampling." Journal of Statistical Software, 36(13), 1-17. URL http://www. jstatsoft. org/v36/i13/.

Brezger A, Kneib T, Lang S (2005). "BayesX: Analyzing Bayesian Structural Additive Regression Models." Journal of Statistical Software, 14(11), 1-22. URL http://www . jstatsoft. org/v14/i11/.

Brown PE (2015). "Model-Based Geostatistics the Easy Way." Journal of Statistical Software, 63(12), 1-24. URL http://www.jstatsoft.org/v63/i12/.

Calenge C (2007). "Exploring Habitat Selection by Wildlife with adehabitat." Journal of Statistical Software, 22(6), 1-19. URL http://www. jstatsoft.org/v22/i06/. 
Davies TM, Bryant D (2013). "On Circulant Embedding for Gaussian Random Fields in R." Journal of Statistical Software, 55(9), 1-21. URL http://www. jstatsoft.org/v55/i09/.

Davies TM, Hazelton ML, Marshall JC (2011). "sparr: Analyzing Spatial Relative Risk Using Fixed and Adaptive Kernel Density Estimation in R." Journal of Statistical Software, 39(1), 1-14. URL http://www.jstatsoft.org/v39/i01/.

Finley AO, Banerjee S, Carlin BP (2007). "spBayes: An R Package for Univariate and Multivariate Hierarchical Point-Referenced Spatial Models." Journal of Statistical Software, 19(4), 1-24. URL http://www.jstatsoft.org/v19/i04/.

Finley AO, Banerjee S, EGelfand A (2015). "spBayes for Large Univariate and Multivariate Point-Referenced Spatio-Temporal Data Models." Journal of Statistical Software, 63(13), 1-28. URL http://www. jstatsoft.org/v63/i13/.

Gabriel E, Rowlingson BS, Diggle PJ (2013). "stpp: An R Package for Plotting, Simulating and Analyzing Spatio-Temporal Point Patterns." Journal of Statistical Software, 53(2), 1-29. URL http://www.jstatsoft.org/v53/i02/.

Gaudart J, Graffeo N, Coulibaly D, Barbet G, Rebaudet S, Dessay N, Doumbo OK, Giorgi R (2015). "SPODT: An R Package to Perform Spatial Partitioning." Journal of Statistical Software, 63(16), 1-23. URL http://www. jstatsoft.org/v63/i16/.

Gerber F, Furrer R (2015). "Pitfalls in the Implementation of Bayesian Hierarchical Modeling of Areal Count Data: An Illustration Using BYM and Leroux Models." Journal of Statistical Software, Code Snippets, 63(1), 1-32. URL http://www.jstatsoft.org/v63/c01/.

Gollini I, Lu B, Charlton M, Brunsdon C, Harris P (2015). "GWmodel: An R Package for Exploring Spatial Heterogeneity Using Geographically Weighted Models." Journal of Statistical Software, 63(17), 1-50. URL http://www.jstatsoft.org/v63/i17/.

Goslee SC (2011). "Analyzing Remote Sensing Data in R: The landsat Package." Journal of Statistical Software, 43(4), 1-25. URL http://www. jstatsoft.org/v43/i04/.

Goslee SC, Urban DL (2007). "The ecodist Package for Dissimilarity-based Analysis of Ecological Data." Journal of Statistical Software, 22(7), 1-19. URL http://www . jstatsoft. org/v22/i07/.

Harte D (2010). "PtProcess: An R Package for Modelling Marked Point Processes Indexed by Time." Journal of Statistical Software, 35(8), 1-32. URL http://www. jstatsoft.org/ v35/i08/.

Hengl T, Roudier P, Beaudette D, Pebesma E (2015). "plotKML: Scientific Visualization of Spatio-Temporal Data." Journal of Statistical Software, 63(5), 1-25. URL http://www. jstatsoft.org/v63/i05/.

Jing L, De Oliveira V (2015). "geoCount: An R Package for the Analysis of Geostatistical Count Data." Journal of Statistical Software, 63(11), 1-33. URL http://www . jstatsoft. org/v63/i11/. 
Josselin D (2005). "Interactive Geographical Information System Using Lisp-Stat: Prototypes and Applications." Journal of Statistical Software, 13(6), 1-34. URL http: //www.jstatsoft.org/v13/i06/.

Laurent T, Ruiz-Gazen A, Thomas-Agnan C (2012). "GeoXp: An R Package for Exploratory Spatial Data Analysis." Journal of Statistical Software, 47(2), 1-23. URL http://www. jstatsoft.org/v47/i02/.

Lee D (2013). "CARBayes: An R Package for Bayesian Spatial Modeling with Conditional Autoregressive Priors." Journal of Statistical Software, 55(13), 1-24. URL http://www . jstatsoft.org/v55/i13/.

Leibovici DG (2010). "Spatio-Temporal Multiway Decompositions Using Principal Tensor Analysis on $k$-Modes: The R Package PTAk." Journal of Statistical Software, 34(10), 1-34. URL http://www.jstatsoft.org/v34/i10/.

Lindgren F, Rue H (2015). "Bayesian Spatial Modelling with R-INLA." Journal of Statistical Software, 63(19), 1-25. URL http://www. jstatsoft.org/v63/i19/.

Loecher M, Ropkins K (2015). "RgoogleMaps and loa: Unleashing R Graphics Power on Map Tiles." Journal of Statistical Software, 63(4), 1-18. URL http://www.jstatsoft.org/ v63/i04/.

Millo G, Piras G (2012). "splm: Spatial Panel Data Models in R." Journal of Statistical Software, 47(1), 1-38. URL http://www.jstatsoft.org/v47/i01/.

Paciorek CJ, Lipshitz B, Zhuo W, Prabhat, Kaufman CG, Thomas RC (2015). "Parallelizing Gaussian Process Calculations in R." Journal of Statistical Software, 63(10), 1-23. URL http://www. jstatsoft.org/v63/i10/.

Padoan SA, Bevilacqua M (2015). "Analysis of Random Fields Using CompRandFld." Journal of Statistical Software, 63(9), 1-27. URL http://www. jstatsoft.org/v63/i09/.

Payton QC, McManus MG, Weber MH, Olsen AR, Kincaid TM (2015). "micromap: A Package for Linked Micromaps." Journal of Statistical Software, 63(2), 1-16. URL http: //www.jstatsoft.org/v63/i02/.

Pebesma E (2012). "spacetime: Spatio-Temporal Data in R." Journal of Statistical Software, 51(7), 1-30. URL http://www.jstatsoft.org/v51/i07/.

Pélissier R, Goreaud F (2015). "ads Package for R: A Fast Unbiased Implementation of the $K$-function Family for Studying Spatial Point Patterns in Irregular-Shaped Sampling Windows." Journal of Statistical Software, 63(6), 1-18. URL http://www.jstatsoft. org/v63/i06/.

Perpinán O (2012). "solaR: Solar Radiation and Photovoltaic Systems with R." Journal of Statistical Software, 50(9), 1-32. URL http://www.jstatsoft.org/v50/i09/.

Peterson E, Ver Hoef J (2014). "STARS: An ArcGIS Toolset Used to Calculate the Spatial Information Needed to Fit Spatial Statistical Models to Stream Network Data." Journal of Statistical Software, 56(2), 1-17. URL http://www.jstatsoft.org/v56/i02/. 
Pickle LW, Pearson Jr JB, Carr DB (2015). "micromapST: Exploring and Communicating Geospatial Patterns in US State Data." Journal of Statistical Software, 63(3), 1-25. URL http://www.jstatsoft.org/v63/i03/.

Piras G (2010). "sphet: Spatial Models with Heteroskedastic Innovations in R." Journal of Statistical Software, 35(1), 1-21. URL http://www.jstatsoft.org/v35/i01/.

R Core Team (2014). R: A Language and Environment for Statistical Computing. R Foundation for Statistical Computing, Vienna, Austria. URL http://www.R-project.org/.

Schlather M, Malinowski A, Menck PJ, Oesting M, Strokorb K (2015). "Analysis, Simulation and Prediction of Multivariate Random Fields with Package RandomFields." Journal of Statistical Software, 63(8), 1-25. URL http://www. jstatsoft.org/v63/i08/.

Sigrist F, Künsch HR, Stahel WA (2015). "spate: An R Package for Spatio-Temporal Modeling with a Stochastic Advection-Diffusion Process." Journal of Statistical Software, 63(14), 123. URL http://www. jstatsoft.org/v63/i14/.

Smith BJ, Yan J, Cowles MK (2008). "Unified Geostatistical Modeling for Data Fusion and Spatial Heteroskedasticity with R Package ramps." Journal of Statistical Software, 25(10), 1-21. URL http://www.jstatsoft.org/v25/i10/.

Stasch C, Scheider S, Pebesma E, Kuhn W (2014). "Meaningful Spatial Prediction and Aggregation." Environmental Modelling \& Software, 51(0), 149-165.

Tanimura S, Kuroiwa C, Mizota T (2006). "Proportional Symbol Mapping in R." Journal of Statistical Software, 15(5), 1-7. URL http://www.jstatsoft.org/v15/i05/.

Taylor BM, Davies TM, Rowlingson BS, Diggle PJ (2013). "Igcp: An R Package for Inference with Spatial and Spatio-Temporal Log-Gaussian Cox Processes." Journal of Statistical Software, 52(4), 1-40. URL http://www.jstatsoft.org/v52/i04/.

Taylor BM, Davies TM, Rowlingson BS, Diggle PJ (2015). "Bayesian Inference and Data Augmentation Schemes for Spatial, Spatiotemporal and Multivariate Log-Gaussian Cox Processes in R." Journal of Statistical Software, 63(7), 1-48. URL http://www . jstatsoft. org/v63/i07/.

Umlauf N, Adler D, Kneib T, Lang S, Zeileis A (2015). "Structured Additive Regression Models: An R Interface to BayesX." Journal of Statistical Software, 63(21), 1-46. URL http://www. jstatsoft.org/v63/i21/.

Ver Hoef J, Peterson E, Clifford D, Shah R (2014). "SSN: An R Package for Spatial Statistical Modeling on Stream Networks." Journal of Statistical Software, 56(3), 1-45. URL http: //www. jstatsoft.org/v56/i03/. 


\author{
Affiliation: \\ Edzer Pebesma \\ Institute for Geoinformatics \\ University of Münster \\ Heisenbergstraße 2 \\ 48149 Münster, Germany \\ E-mail: edzer.pebesma@uni-muenster.de \\ URL: http://ifgi.uni-muenster.de/ \\ Roger Bivand \\ Department of Economics \\ Norwegian School of Economics \\ Helleveien 30 \\ N-5045 Bergen, Norway \\ E-mail: Roger.Bivand@nhh.no \\ Paulo Justiniano Ribeiro Jr. \\ LEG (Laboratorio de Estatistica e Geoinformacao) \\ Universidade Federal do Parana \\ Curitiba, PR, Brazil \\ E-mail: paulojus@ufpr.br \\ http://www.leg.ufpr.br/〜paulojus/
}

Journal of Statistical Software

published by the American Statistical Association

Volume 63, Issue 1

January 2015 http://www.jstatsoft.org/

http://www. amstat.org/

Submitted: 2015-01-19

Accepted: 2015-01-19 